\title{
Nutrition activation and dietary intake disparities among US adults
}

\author{
Brent A Langellier ${ }^{1, *}$ and Philip M Massey ${ }^{2}$ \\ 'Department of Health Management and Policy, Drexel University Dornsife School of Public Health, Drexel University, \\ Room 356 Nesbitt Hall, 3215 Market Street, Philadelphia, PA 19104, USA: ${ }^{2}$ Department of Community Health and \\ Prevention, Drexel University Dornsife School of Public Health, Drexel University, Philadelphia, PA, USA
}

Submitted 30 November 2015: Final revision received 8 April 2016: Accepted 12 May 2016: First published online 13 June 2016

\begin{abstract}
Objective: To introduce the concept 'nutrition activation' (the use of health and nutrition information when making food and diet decisions) and to assess the extent to which nutrition activation varies across racial/ethnic groups and explains dietary disparities.

Design: Cross-sectional sample representative of adults in the USA. Primary outcome measures include daily energy intake and consumption of sugarsweetened beverages (SSB), fast foods and sit-down restaurant foods as determined by two $24 \mathrm{~h}$ dietary recalls. We use bivariate statistics and multiple logistic and linear regression analyses to assess racial/ethnic disparities in nutrition activation and food behaviour outcomes.

Setting: USA.

Subjects: Adult participants ( $n$ 7825) in the 2007-2010 National Health and Nutrition Examination Survey.

Results: Nutrition activation varies across racial/ethnic groups and is a statistically significant predictor of SSB, fast-food and restaurant-food consumption and daily energy intake. Based on the sample distribution, an increase from the 25 th to 75 th percentile in nutrition activation is associated with a decline of about $377 \mathrm{~kJ}$ $(90 \mathrm{kcal}) / \mathrm{d}$. Increased nutrition activation is associated with a larger decline in SSB consumption among whites than among blacks and foreign-born Latinos. Fastfood consumption is associated with a larger 'spike' in daily energy intake among blacks $(+1582 \mathrm{~kJ}(+378 \mathrm{kcal}) / \mathrm{d})$ than among whites $(+678 \mathrm{~kJ}(+162 \mathrm{kcal}) / \mathrm{d})$.

Conclusions: Nutrition activation is an important but understudied determinant of energy intake and should be explicitly incorporated into obesity prevention interventions, particularly among racial/ethnic minorities.
\end{abstract}

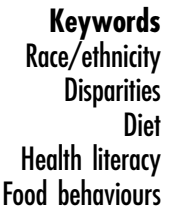

It is of critical importance to identify effective strategies to reverse secular increases in overweight and obesity prevalence that have occurred in most developed countries over the last several decades ${ }^{(1,2)}$. To achieve this, we must better understand the multilevel factors and causal pathways that generate substantial disparities in overweight and obesity prevalence between racial/ethnic groups and across socio-economic strata. In the USA, for example, $76.9 \%$ of Latino adults were overweight or obese in 2007-2008, compared with $73.7 \%$ of blacks and $67.5 \%$ of whites ${ }^{(3)}$. Disparities in overweight and obesity are likely a reason why $45 \%$ of Latino men and $40 \%$ of black men born in the USA in 2000 will develop diabetes in their lifetime, compared with just $27 \%$ of white men and $31 \%$ of white women ${ }^{(4)}$.

Obesity is fundamentally the result of energy imbalance; weight gain results when energy intake exceeds expenditure $^{(5,6)}$. Thus, a strategy to combat the obesity epidemic is to support populations to reduce energy intake through improved diet healthfulness. Diet is shaped by multilevel public policy, environmental, social, cultural, interpersonal and individual factors ${ }^{(7-11)}$. At the individual level, diet is shaped by psychosocial factors including knowledge, attitudes and beliefs ${ }^{(12)}$. Unhealthy diet has been linked to a variety of sociodemographic factors, particularly poverty and low educational attainment ${ }^{(13-16)}$. More recently, researchers have posited that environmental factors may drive disparities in food purchasing and diet, since low-income populations and racial/ethnic minorities tend to live in neighbourhoods with fewer supermarkets and more fast-food restaurants, liquor stores and other unhealthy food outlets $^{(10,17,18)}$. Multiple studies have found that high access to fast-food restaurants is, in fact, associated with increased consumption of fast foods ${ }^{(10,19)}$. Frequent consumption of 
fast foods is associated with poorer diet quality, although less is known about the impacts of other types of restaurant ${ }^{(10,20-22)}$.

In the USA, federal programmes have developed several tools geared towards helping individuals make healthy food choices. For example, dietary recommendations and guidelines are disseminated through national campaigns such as MyPlate, which provides a pictorial, plate-based representation of recommended proportions of a meal that should be from different food groups (e.g. protein, vegetables, dairy). Packaged foods include food labels that provide information on ingredients lists, nutrient contents, recommended serving sizes and the contribution of the item towards daily intake recommendations (i.e. the "percent daily value'). In Latin America, the European Union and several other countries, governments have also mandated nutrition facts labels, developed more comprehensible, consumer-friendly health information, and/or limited food companies' ability to make health claims on food packages $^{(23,24)}$. While the development and availability of nutrition labels on packaged foods has been a great public health success, consumer use and comprehension of nutrition labels vary greatly based on sociodemographic characteristics, knowledge, literacy levels and motivation ${ }^{(25)}$. Contributing to consumer confusion and misunderstandings is the variation between front- and back-of-package food labels, which can lead to misleading information, inappropriate portion sizes and confusing calculations ${ }^{(26)}$.

Literacy and numeracy skills are important concepts in the nutrition literature and are associated with food label comprehension, as well as food label viewing time and portion-size estimation ${ }^{(27-29)}$. Moreover, measures of health literacy, including the Newest Vital Sign, have been developed to measure the concept within the context of nutrition labelling ${ }^{(30)}$. Broadly, health literacy is defined as the ability to obtain, process and understand basic health information to make informed health-related decisions $^{(31,32)}$. While the Newest Vital Sign has been an important development in the measurement of health literacy, concerns arise that the measure is not culturally competent and that the Newest Vital Sign in fact measures a functional nutrition literacy concept that is distinct from health literacy ${ }^{(33,34)}$.

Applying the widely used health literacy framework proposed by Nutbeam, functional nutrition literacy can be defined as the ability to comprehend nutrition information presented on food labels ${ }^{(31)}$. Application or use of information is another important facet that is not captured by functional nutrition literacy, which focuses more on cognitive ability. Importantly, potential mechanisms through which nutrition information could impact diet quality must not only include individuals' ability to read and understand nutrition information and food labels, but must also extend to use and application of nutrition labels for food purchasing. Similarly, it is important to understand how social, cultural and economic factors influence both functional nutrition literacy (i.e. ability to use) and actual use and application of available information.

A parallel yet distinct literature to health literacy that continues to expand and gain traction in the field has found that 'activated' patients who are more confident and engaged in their health care demonstrate increased satisfaction with care and better outcomes. Patient activation refers to patients' understanding of their own roles in the care process and having the knowledge, skill and confidence to manage their own health and health care $^{(35)}$. A large and growing literature suggests that more activated patients are more likely to utilize preventive health care (e.g. regular check-ups, screenings and immunizations), engage in healthy behaviours (e.g. healthy diet and regular exercise) and avoid unhealthy behaviours (e.g. smoking and illegal drug use) ${ }^{(35-40)}$.

The aforementioned literature has demonstrated that patient activation and health literacy are distinct concepts and that both contribute to variations in health behaviours. The health literacy and patient activation literatures, which have largely been framed within the context of health care, may have implications for how we understand the mechanisms through which available nutrition information may impact an individual's diet. In the current study we present and explore the concept of 'nutrition activation'. Drawing from the patient activation literature, we define nutrition activation as the extent to which individuals actually use available health and nutrition information when selecting between food and beverage items for purchase or consumption. In contrast to nutrition literacy, a related but distinct concept, nutrition activation refers to actual use and application of information, rather than the cognitive abilities necessary to accurately process that information.

\section{Conceptual framework}

In the current study we seek to use nationally representative data from the USA to disentangle the relationship between race/ethnicity, nutrition activation, food behaviours (e.g. consumption of restaurant food) and diet healthfulness. We present the conceptual framework that guides the study in Fig. 1. The framework serves as a visual representation of the following hypotheses:

H1. Racial/ethnic groups vary in their levels of nutrition activation.

H2. Nutrition activation is associated with food-related behaviours (i.e. consumption of restaurant foods and sugar-sweetened beverages (SSB)) and diet.

H3. Race/ethnicity moderates the relationship between nutrition activation, food-related behaviours and diet.

H4. Race/ethnicity moderates the relationship between restaurant-food consumption and diet. 


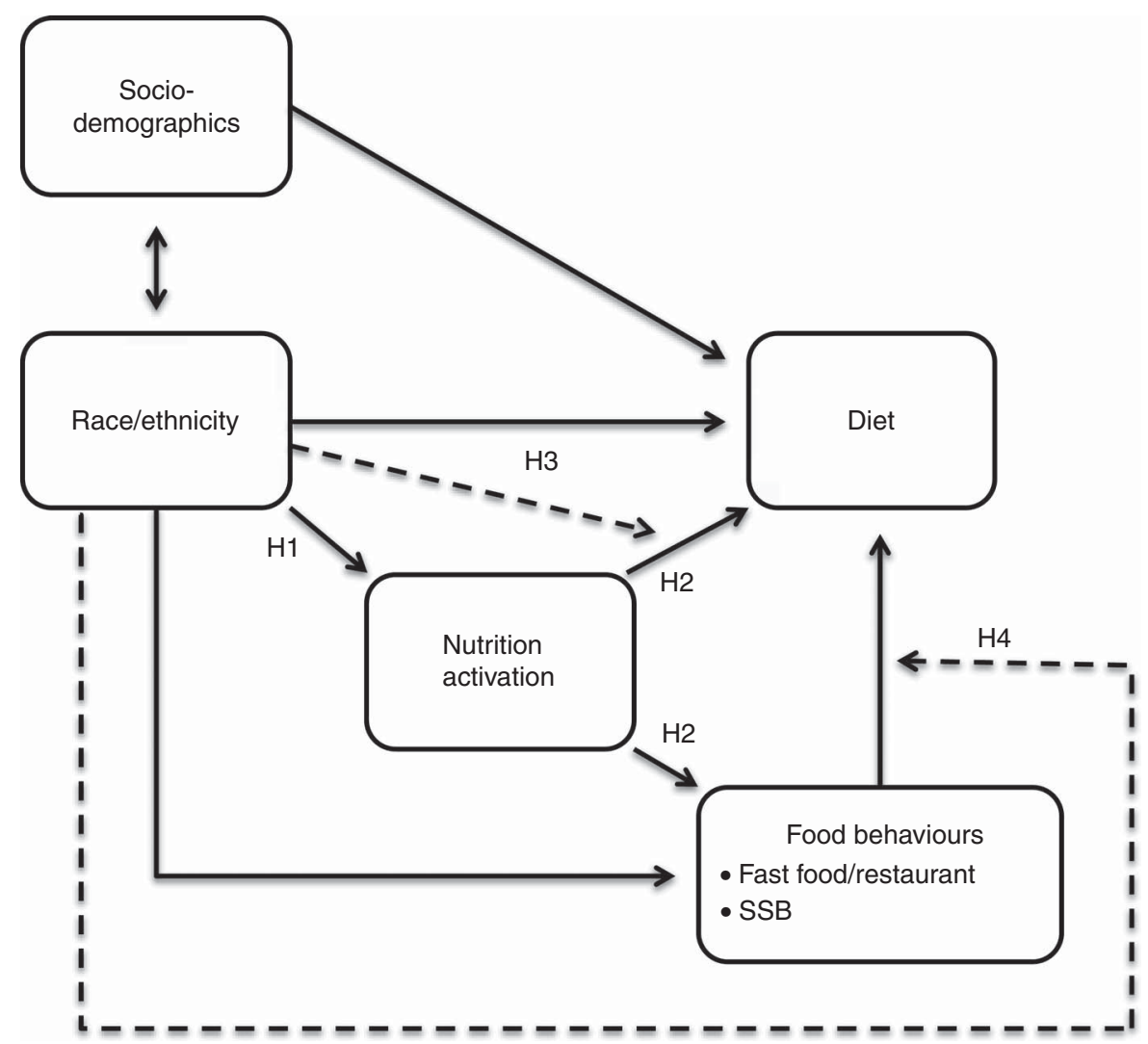

Fig. 1 Conceptual framework of the posited relationship ( - , direct effect; - - - - -, effect modifier) between race/ethnicity, nutrition activation and food behaviours $(\mathrm{H} 1-\mathrm{H} 4$, hypotheses 1 to 4 ; SSB, sugar-sweetened beverages)

Our framework and hypotheses are based on the literatures regarding health literacy and health disparities in nutrition and diet. Documented racial/ethnic differences in health literacy suggest the potential for disparities in nutrition activation, which may be an important but underexplored mechanism for disparities in food behaviours and diet healthfulness ${ }^{(5,41,42)}$. Complex interrelationships between race/ethnicity, nutrition activation, food behaviours and diet healthfulness are important to examine because they may be substantively important for identifying pathways that produce disparities as well as addressing disparities. Specifically, we believe racial/ ethnic minorities, particularly foreign-born Latinos, may benefit less from nutrition activation because nutrition information is typically not culturally or linguistically tailored for these groups. If highly activated minorities receive less of an advantage in diet healthfulness, this would likely underscore the need for culturally competent nutrition information and food labels. Finally, a broad literature suggests different food cultures both between (e.g. whites and blacks) and within (e.g. US- and foreign-born Latinos) racial/ethnic groups ${ }^{(43-49)}$. Understanding whether the contribution of foods prepared away from home to diet healthfulness varies across racial/ethnic groups will inform strategies to reduce disparities.

\section{Materials and methods}

\section{Data source}

We use data from the public-use data files of the 2007-2010 National Health and Nutrition Examination Survey (NHANES). These data are publicly available through the website of the National Center for Health Statistics (http://www.cdc.gov/nchs/nhanes/) and do not contain personally identifying information. Thus, the present study does not meet the definition of human subjects research and no institutional review board approval was sought.

NHANES is a continuous series of annual studies that has been conducted since 1999 and is designed to assess the health and nutritional status of adults and children in the USA. NHANES uses a complex, multistage sampling design to obtain a sample representative of the noninstitutionalized US population. NHANES uses oversampling to produce sub-samples representative of particular under-represented groups, including children and adolescents, people living in low-income households and racial/ethnic minorities. NHANES includes a core interview component, a physical examination and two $24 \mathrm{~h}$ dietary recalls. Importantly for the present study, the first $24 \mathrm{~h}$ recall was conducted in person after the physical examination; the second recall occurred over the telephone three to ten days later. At the conclusion of the 
second (telephone) recall, participants were also asked to participate in an additional module regarding various consumer behaviours, primarily regarding food purchasing. Further details on the sampling strategy and study design employed by NHANES are available elsewhere ${ }^{(50)}$.

\section{Analytic sub-sample}

In the present study we restrict our analyses to 7765 adult NHANES participants who met the following inclusion criteria: (i) age $\geq 20$ years; (ii) self identified as white, black or Latino (i.e. we excluded those characterized as 'other' or 'multiracial'); (iii) participated in at least one of two $24 \mathrm{~h}$ dietary recalls; and (iv) had complete data regarding our independent and dependent variables. Of the 20686 total participants in the 2007-2010 NHANES, we exclude from our analyses 8533 who did not meet the age criteria, 596 who did not self-identify as white, black or Latino, 891 who did not participate in at least one day of the dietary recall and 2107 who did not participate in the consumer behaviour telephone follow-up. We further exclude participants with incomplete data regarding educational attainment $(n 7)$, income $(n 723)$ or marital status $(n 4)$.

\section{Outcome variables}

We examine racial/ethnic disparities in four outcomes: (i) daily energy consumption; (ii) consumption of foods or beverages from a fast-food restaurant; (iii) consumption of foods or beverages from a sit-down restaurant; and (iv) consumption of SSB. Data for all outcomes is from either one or two days of assessment via $24 \mathrm{~h}$ dietary recalls. We operationalize daily energy consumption as mean consumption of energy across the two recall days; for those who participated in only one day of recall, we assess daily energy consumption during that one day. The nutrient contents of diets reported in NHANES are determined using the US Department of Agriculture's Food and Nutrient Database for Dietary Studies. We define consumption of fast food or restaurant food as a binary variable indicating whether participants consumed any food or beverage item from a fast-food or sit-down restaurant, respectively, on a given day. Participants self-report the source (e.g. supermarket, restaurant) of each food item that they have consumed. We define consumption of SSB as the number of items consumed that fall within this category. We use US Department of Agriculture food codes in the original NHANES data set to identify SSB.

\section{Independent variables}

\section{Race/ethnicity}

The focal independent variable in the present study is participants' self-reported race/ethnicity. We characterize race/ethnicity as follows: (i) white; (ii) black; (iii) US-born Latino; and (iv) foreign-born Latino. We exclude participants who self-identified as 'multiracial' or 'other' from our analyses, because the lack of more detailed information regarding the race/ethnicity of these participants would preclude us from drawing conclusions about disparities relative to other groups (i.e. whites). We separate US- from foreign-born Latinos because a broad literature has established that health behaviours, including diet, vary substantially between these groups ${ }^{(44,51)}$.

\section{Nutrition activation}

We define nutrition activation as the extent to which people actively use available nutrition information to inform their decisions when shopping for food. We develop an index of nutrition activation using information from six NHANES items regarding use of nutrition facts panels, ingredients lists, serving size information, percent daily values, health claims and expiration dates. These items are assessed via questions with the following form: 'How often do you use (the list of ingredients on a food label) when deciding to buy a food product? Would you say always, most of the time, sometimes, rarely, or never?'

We believe that these indicators of nutrition information use are all sub-measures of a larger nutrition activation construct, because they each represent a behaviour consumers actively engage in when selecting between packaged food items. To test this belief, we conducted a factor analysis of the six ordinal items using a polychoric correlation matrix. All six items loaded most strongly on a single factor, which we interpret as support for a single construct. To aid interpretation of our results, we also constructed a more intuitive 'nutrition activation index' by summing responses to questions regarding each of the six information sources using the following scoring: 'never' $=0$, 'rarely' $=1$, 'sometimes' $=2, \quad$ 'most of the time' $=3$, 'always' $=4$. This results in an index with response options ranging from 0 to 24 . In sensitivity analyses, we ran all multivariable models separately with the factor scale and the additive index. The results for all models were qualitatively equivalent, so we included the additive model (rather than the factor) because we believe it is a more intuitive measure of the underlying nutrition activation construct. For descriptive purposes, we also present the proportion of participants who report either 'always' or 'most of the time' for each of the outcomes.

\section{Potential confounders}

In multivariable analyses we control for several potential confounders that may be associated with race/ethnicity, nutrition activation and diet. These include participants' age, gender, marital status, educational attainment, household income, family size and the day of the week of the $24 \mathrm{~h}$ dietary recall. These variables are assessed using standard instruments and methodologies; further details are available on the NHANES website (http://www.cdc.gov/nchs/nhanes/).

\section{Statistical analyses}

We present the percentage distribution of all categorical variables and the mean and $95 \%$ confidence interval for all 
continuous variables. Because our primary interest is in identifying and examining racial/ethnic disparities, we stratify each of these statistics by participants' race/ ethnicity.

We further present six logistic regression models to assess the extent to which food behaviours vary based on race/ethnicity and the nutrition activation index. Outcomes for these models include the following: (i) consumption of any food or beverage item from a fast-food restaurant on recall day 1; (ii) consumption of any food or beverage item at a sit-down restaurant on recall day 1; and (iii) consumption of any SSB on recall day 1. Each model adjusts for race/ethnicity, nutrition activation index and all potential confounders outlined above. For each outcome, we present a model that further adjusts for an interaction between race/ethnicity and nutrition activation. We use dichotomous outcomes for each of these models because the distributions of continuous outcomes (e.g. number of SSB consumed) were highly skewed and right tailed. We were unable to identify a transformation of the outcomes (e.g. square root) that would approach a normal distribution.

Finally, we present a series of four linear regression models of mean energy consumption across the two days of recall (or for one day among those participants who responded only to one day). Model 1 predicts energy consumption based on race/ethnicity, the nutrition activation index, a variable representing consumption of fast food or restaurant food on one or both days of recall, the mean number of SSB and alcoholic beverages consumed across the recall days, and potential confounders. Models 2, 3 and 4 further include interaction terms aligned with our hypotheses and conceptual framework. Specifically, models 2 and 3 include interactions between fast-food and restaurant-food consumption, respectively, and race/ethnicity to understand whether the contribution of fast-food and restaurant-food consumption, respectively, to daily energy intake varies across racial/ethnic groups. Model 4 includes interactions between race/ethnicity and the nutrition activation index to understand whether the energetic effects of being 'activated' vary by race/ethnicity.

For all analyses, we use sample weights included in the NHANES public-use files that account for non-response, the complex design of the study and post-stratification. Further details regarding the construction and use of samples weights are available on the website of the National Center for Health Statistics. We conducted all analyses using the statistical software package Stata version 12 .

\section{Results}

In Table 1 we present sociodemographic characteristics and food behaviour outcomes stratified by participants' race/ethnicity. US-born and foreign-born Latinos in the sample were, on average, younger than whites and blacks. Over half of foreign-born Latinos had less than a highschool education compared with one-quarter of blacks and US-born Latinos and one-eighth of whites. Mean income among all minority groups was significantly $(P<0 \cdot 001)$ lower than that than among whites.

Food behaviours also varied across racial/ethnic groups. Nearly $40 \%$ of blacks and US-born Latinos reported consuming fast food on recall day 1 , compared with less than $30 \%$ of whites and foreign-born Latinos. In contrast, consumption at sit-down restaurants was lower among blacks and foreign-born Latinos than among whites and US-born Latinos. These patterns were consistent for the second day of recall. Relative to racial/ethnic minorities, whites were less likely to consume SSB. Mean daily energy consumption was lowest among foreign-born Latinos $(8289 \mathrm{~kJ}(1981 \mathrm{kcal}) / \mathrm{d})$ and highest among US-born Latinos (9201 kJ (2199 kcal)/d).

In Table 2 we report on nutrition activation; that is, the percentage of participants who report that they 'always' or 'most of the time' use various sources of information regarding the nutritional content and healthfulness of the packaged foods they purchase. Across the entire sample, the most frequently reported information used when purchasing packaged food items was the expiration date ( $82 \%$ of the sample) followed by the nutrition facts panel ( $40 \%$ of the sample). In general, foreign-born Latinos reported greater use of these information sources than other groups. This is evident in the average nutrition activation score of $14 \cdot 1$ among foreign-born Latinos, relative to $12 \cdot 7$ among whites and US-born Latinos and 13.4 among blacks, respectively $(P<0.001)$.

In Table 3 we present the results of six logistic regression models predicting consumption of fast food (models 1 and 2), restaurant food (models 3 and 4) and SSB (models 5 and 6) on the first day of recall. These results reveal several interesting patterns. Models 1 and 3 suggest that, after adjustment for other factors, many differences in food behaviours between racial/ethnic groups are no longer statistically significant. The one exception is that foreign-born Latinos have $30 \%$ greater odds of consuming SSB relative to whites $(P<0 \cdot 05)$. Age, gender and educational attainment are also significantly associated with the food outcomes. Income is positively associated with consumption at restaurants, but negatively associated with consumption of SSB. Interestingly, nutrition activation is negatively associated with fast-food and SSB consumption, but has no impact on restaurant-food consumption. After adjustment for other factors, a one-point increase in the nutrition activation index is associated with a $1.8 \%$ decline in the odds of fast-food consumption $(P<0.05)$ and a $7 \cdot 2 \%$ decline in the odds of consuming at least one SSB $(P<0 \cdot 01)$. The interaction terms in model 2 suggest that there is no variation across racial/ethnic groups in the impact of nutrition activation on consumption of fast food. In contrast, model 6 indicates that the benefit of nutrition 
activation in lowering SSB consumption is less among blacks $(P<0 \cdot 01)$ and foreign-born Latinos $(P<0 \cdot 01)$ than whites.

We present the results of three linear regression models predicting mean daily energy consumption in Table 4. In model 1 , we adjust for sociodemographic characteristics, nutrition activation and consumption of fast food, restaurant food, SSB, diet beverages and alcoholic beverages. After adjustment for the other factors, blacks and foreign-born Latinos consume less energy than whites $(P<0.05$ in both cases), while there is no significant difference between US-born Latinos and whites. A one-point increase in the nutrition activation index is associated with a decline of $54 \mathrm{~kJ}$ (13 kcal; $P<0 \cdot 001)$. Further, consumption of fast food is associated with an increase of $837 \mathrm{~kJ}(200 \mathrm{kcal} ; P<0.001)$ and consumption of restaurant food with a $598 \mathrm{~kJ}$ (143 kcal) increase $(P<0 \cdot 01)$, while consumption of each additional SSB is associated with an increase of $816 \mathrm{~kJ}(195 \mathrm{kcal}$; $P<0 \cdot 001)$. In model 2 we further include interaction terms to assess whether the impact of fast-food consumption on daily energy consumption varies across racial/ethnic groups. We find that fast-food consumption among blacks is associated with an increase in daily energy consumption that is $904 \mathrm{~kJ}(216 \mathrm{kcal})$ greater than the increase among whites $(P<0.05)$. We find no such difference across race/ ethnicities in the impact of eating at sit-down restaurants. In model 4 we include interaction terms to assess whether the impact of nutrition activation varies by race/ethnicity. We find no significant difference across racial/ethnic groups in the association between the nutrition activation index and daily energy consumption.

\section{Discussion}

A robust literature has documented racial/ethnic disparities in diet and obesity ${ }^{(52)}$. In general, whites and foreign-born Latinos in the USA demonstrate more healthful diets and lower obesity rates relative to blacks and US-born Latinos ${ }^{(2)}$. Interestingly, the 'immigrant health advantage' experienced by foreign-born Latinos erodes over time, such that longer-tenured immigrants tend to have similar health status to their US-born counterparts ${ }^{(53-55)}$. Further literature from the field of health literacy suggests that racial/ethnic minorities also experience disadvantage relative to whites in access and use of health information ${ }^{(56-58)}$. In the current study we attempt to assess whether the above patterns are linked by examining the extent to which nutrition activation (i.e. use of nutrition information) explains racial/ethnic disparities in food behaviours and diet healthfulness.

The results of the present study provide several insights for diet and obesity research and practice. An important study finding is that, in support of our first hypothesis, racial/ethnic groups demonstrate somewhat different levels of nutrition activation, with nutrition activation 
Table 2 Nutrition activation by race/ethnicity, National Health and Nutrition Examination Survey 2007-2010 ( $n$ 7765)

\begin{tabular}{|c|c|c|c|c|c|c|c|c|c|c|c|}
\hline & \multicolumn{2}{|c|}{ White } & \multicolumn{2}{|c|}{ Black } & \multicolumn{2}{|c|}{ US-born Latino } & \multicolumn{2}{|c|}{ Foreign-born Latino } & \multicolumn{2}{|c|}{ Total } & \multirow[b]{2}{*}{$P$ value } \\
\hline & $\begin{array}{l}\% \text { or } \\
\text { mean }\end{array}$ & $95 \% \mathrm{Cl}$ & $\begin{array}{l}\% \text { or } \\
\text { mean }\end{array}$ & $95 \% \mathrm{Cl}$ & $\begin{array}{l}\% \text { or } \\
\text { mean }\end{array}$ & $95 \% \mathrm{Cl}$ & $\begin{array}{l}\% \text { or } \\
\text { mean }\end{array}$ & $95 \% \mathrm{Cl}$ & $\begin{array}{l}\% \text { or } \\
\text { mean }\end{array}$ & $95 \% \mathrm{Cl}$ & \\
\hline \multicolumn{12}{|c|}{ Nutrition activation items (\%) } \\
\hline $\begin{array}{l}\text { Use ingredients } \\
\text { list }\end{array}$ & $28 \cdot 2$ & $25 \cdot 9,30 \cdot 6$ & $34 \cdot 8$ & $31 \cdot 2,38 \cdot 3$ & $27 \cdot 0$ & $22 \cdot 4,31 \cdot 5$ & $35 \cdot 8$ & $32 \cdot 7,39 \cdot 0$ & $29 \cdot 5$ & $27 \cdot 8,31 \cdot 2$ & $<0.001$ \\
\hline Use serving size & 28.5 & $26 \cdot 2,30 \cdot 7$ & $32 \cdot 8$ & $29 \cdot 6,36 \cdot 0$ & $25 \cdot 9$ & $21 \cdot 6,30 \cdot 1$ & 34.6 & $32 \cdot 0,37 \cdot 2$ & $29 \cdot 3$ & $27 \cdot 5,31 \cdot 1$ & 0.004 \\
\hline $\begin{array}{l}\text { Use percent daily } \\
\text { value }\end{array}$ & $22 \cdot 2$ & $20 \cdot 3,24 \cdot 1$ & $29 \cdot 5$ & $26 \cdot 4,32 \cdot 5$ & $24 \cdot 5$ & $20 \cdot 9,28 \cdot 1$ & $36 \cdot 9$ & $33 \cdot 3,40 \cdot 5$ & $24 \cdot 2$ & $22 \cdot 6,25 \cdot 8$ & $<0.001$ \\
\hline Use health claims & 23.4 & $21 \cdot 5,25 \cdot 2$ & 34.4 & $31 \cdot 4,37 \cdot 4$ & $32 \cdot 1$ & $26 \cdot 5,37 \cdot 7$ & $40 \cdot 0$ & $36 \cdot 6,43 \cdot 3$ & $26 \cdot 3$ & $24 \cdot 9,27 \cdot 7$ & $<0.001$ \\
\hline $\begin{array}{l}\text { Use expiration } \\
\text { date }\end{array}$ & $80 \cdot 8$ & $79 \cdot 2,82 \cdot 4$ & $88 \cdot 0$ & $86 \cdot 6,89 \cdot 5$ & $85 \cdot 5$ & $81 \cdot 5,89.5$ & 83.5 & $80 \cdot 1,87 \cdot 0$ & $82 \cdot 0$ & $80 \cdot 8,83 \cdot 3$ & $<0.001$ \\
\hline $\begin{array}{l}\text { Use nutrition facts } \\
\text { panel }\end{array}$ & $41 \cdot 1$ & $38 \cdot 7,43 \cdot 5$ & $37 \cdot 1$ & $34 \cdot 0,40 \cdot 2$ & $37 \cdot 4$ & $33 \cdot 4,41.4$ & $40 \cdot 0$ & $37 \cdot 2,42 \cdot 8$ & $40 \cdot 4$ & $38 \cdot 7,42 \cdot 1$ & $0 \cdot 107$ \\
\hline $\begin{array}{l}\text { Nutrition activation } \\
\text { index }\end{array}$ & $12 \cdot 7$ & $12 \cdot 5,12 \cdot 9$ & $13 \cdot 4$ & $13 \cdot 1,13 \cdot 8$ & $12 \cdot 7$ & $12 \cdot 2,13 \cdot 3$ & $14 \cdot 1$ & $13 \cdot 8,14 \cdot 5$ & $12 \cdot 9$ & $12 \cdot 7,13 \cdot 1$ & $<0.001$ \\
\hline
\end{tabular}

Percentages refer to the percentage of participants within each racial/ethnic stratum who engage in a given activity 'most of the time' or 'always'. The nutrition activation index is a sum of scores on all other items, with responses for each item ranging from 'never' (score $=0)$ to 'always' (score $=4$ ).

higher among foreign-born Latinos and blacks than whites or US-born Latinos. Comparatively higher activation levels among foreign-born Latinos and blacks contrast with our a priori expectations, as well as patterns observed in the broader field of health literacy ${ }^{(5,41,42)}$. This higher engagement in food choices and decision making may contribute to the immigrant advantage in diet and health.

Consistent with our second hypothesis, nutrition activation is an important determinant of food-related behaviours. Mean nutrition activation among our sample was 13 on a 24-point scale, with an interquartile range of 10-17. In multivariable analyses we found that, after adjustment for other factors, a one-point increase in nutrition activation was associated with roughly a $54 \mathrm{~kJ}$ (13 kcal) decline in daily intake. Thus, an increase from the 25 th to 75 th percentile in nutrition activation would be associated with a decline of about $377 \mathrm{~kJ}(90 \mathrm{kcal}) / \mathrm{d}$. A frequently used, although admittedly simplistic, estimate is that an increase (decrease) of $14644 \mathrm{~kJ}$ (3500 kcal) is roughly equivalent to an $0.45 \mathrm{~kg}$ ( $1 \mathrm{lb})$ increase (decrease) in body weight ${ }^{(59)}$. Thus, moving a person at the 25 th percentile in nutrition activation to the 75 th percentile would be associated with approximately a $4.10 \mathrm{~kg}$ (9lb) decrease in weight over the course of one year.

Our third hypothesis was that the relationship between nutrition activation and food behaviours would vary across racial/ethnic groups. Specifically, we believed that minorities, and particularly foreign-born Latinos who tend to primarily speak Spanish, would benefit less from using nutrition information than whites. We found that nutrition activation is associated with frequency of fast-food and sit-down restaurant-food consumption and daily energy intake; however, the impact of nutrition activation on these outcomes was not significantly different across groups. This may suggest that public health efforts should focus broadly on activating consumers.
In contrast, the relationship between nutrition activation and SSB consumption was significantly reduced among blacks and foreign-born Latinos relative to whites. This suggests that greater consumption of SSB among blacks and foreign-born Latinos at the group level may be driven by disparities at the higher end of the nutrition activation spectrum (i.e. low-activation blacks and whites are equally likely to consume SSB, but high-activation whites are less likely than high-activation blacks).

A further important finding of the current study is that racial/ethnic groups vary in the 'bump' that eating at a fastfood or sit-down restaurant makes towards daily energy intake. For example, whites who had eaten at a restaurant demonstrated daily intake approximately $678 \mathrm{~kJ}$ (162 kcal) greater than those who had not; this energy spike was approximately $1590 \mathrm{~kJ}$ (380 kcal) among blacks. The 'bump' in energy from eating at sit-down restaurants was greatest among US-born Latinos; however, the difference between US-born Latinos and whites was not statistically significant. Given the frequency with which individuals of all race/ethnicity report consuming prepared meals, these differences may be an important pathway for obesity disparities. Thus, interventions should seek to not only reduce the frequency with which individuals consume meals prepared outside of home, but also to improve food decision making when people do eat at restaurants.

It is important to stress that we conceptualize nutrition activation as the extent to which individuals use health and nutrition information when selecting between food and beverage items for purchase or consumption. In other words, nutrition activation is the application of relevant information to food-related behaviours. This is a distinct concept from functional nutrition literacy, which refers to the cognitive ability necessary to process and understand nutrition information. A plausible explanation for our finding that nutrition activation has less of an impact on SSB consumption among minorities is that functional 
Table 3 Logistic regression models predicting the probability of consuming fast food, restaurant food and sugar-sweetened beverages (SSB), National Health and Nutrition Examination Survey 2007-2010 ( $n$ 7765)

\begin{tabular}{|c|c|c|c|c|c|c|c|c|c|c|c|c|}
\hline & \multicolumn{2}{|r|}{ (1) } & \multicolumn{2}{|c|}{$(2)$} & \multicolumn{2}{|r|}{ (3) } & \multicolumn{2}{|c|}{ (4) } & \multicolumn{2}{|r|}{ (5) } & \multicolumn{2}{|r|}{ (6) } \\
\hline & \multicolumn{2}{|c|}{ Fast food } & \multicolumn{2}{|c|}{ Fast food } & \multicolumn{2}{|c|}{ Restaurant food } & \multicolumn{2}{|c|}{ Restaurant food } & \multicolumn{2}{|c|}{ SSB } & \multicolumn{2}{|c|}{ SSB } \\
\hline & OR & $95 \% \mathrm{Cl}$ & OR & $95 \% \mathrm{Cl}$ & OR & $95 \% \mathrm{Cl}$ & OR & $95 \% \mathrm{Cl}$ & OR & $95 \% \mathrm{Cl}$ & OR & $95 \% \mathrm{Cl}$ \\
\hline Age & $0.977^{\star \star \star}$ & $0.972,0.982$ & $0.977^{\star \star \star}$ & $0.972,0.982$ & $0.992^{*}$ & $0.986,0.998$ & $0.992^{*}$ & $0.986,0.998$ & $0.970^{\star \star \star}$ & $0.966,0.973$ & $0.970^{\star \star \star}$ & $0.966,0.974$ \\
\hline Male gender & $1 \cdot 197^{\star}$ & $1.000,1.432$ & $1 \cdot 187$ & $0.991,1.423$ & $1 \cdot 191^{\star \star}$ & $1.056,1.344$ & $1 \cdot 197^{\star \star}$ & $1.065,1.346$ & $1.606^{\star \star *}$ & $1.380,1.869$ & $1.578^{\star * *}$ & $1.354,1.839$ \\
\hline \multicolumn{13}{|l|}{ Marital status } \\
\hline Married & \multicolumn{2}{|r|}{ Ref. } & \multicolumn{2}{|r|}{ Ref. } & \multicolumn{2}{|r|}{ Ref. } & \multicolumn{2}{|r|}{ Ref. } & \multicolumn{2}{|r|}{ Ref. } & \multicolumn{2}{|c|}{ Rref. } \\
\hline Never married & 0.968 & $0.798,1.176$ & 0.970 & $0.800,1.175$ & 1.004 & $0.794,1.270$ & 1.003 & $0.792,1.269$ & 0.775 & $0.585,1.027$ & 0.777 & $0.588,1.028$ \\
\hline Div/wid/sep & $1 \cdot 167$ & $0.931,1.464$ & $1 \cdot 165$ & $0.930,1.461$ & 1.027 & $0.830,1.271$ & 1.028 & $0.830,1.272$ & $1 \cdot 240$ & $0.958,1.604$ & $1 \cdot 234$ & $0.954,1.596$ \\
\hline \multicolumn{13}{|l|}{ Educational attainment } \\
\hline$<\mathrm{HS}$ & \multicolumn{2}{|c|}{ Ref. } & \multicolumn{2}{|c|}{ Ref. } & \multicolumn{2}{|c|}{ Ref. } & \multicolumn{2}{|c|}{ Ref. } & \multicolumn{2}{|c|}{ Ref. } & \multicolumn{2}{|c|}{ Rref. } \\
\hline $\mathrm{HS}$ & $1.322^{*}$ & $1.046,1.669$ & $1.320^{\star}$ & $1.044,1.669$ & 1.189 & $0.882,1.604$ & $1 \cdot 190$ & $0.882,1.606$ & $1 \cdot 119$ & $0.922,1.357$ & $1 \cdot 124$ & $0.927,1.362$ \\
\hline$>\mathrm{HS}$ & 1.012 & $0.804,1.275$ & 1.013 & $0.804,1.277$ & $1 \cdot 313^{\star}$ & $1.019,1.692$ & $1 \cdot 313^{\star}$ & $1.019,1.692$ & $0.688^{\star \star}$ & $0.556,0.851$ & $0.692^{\star \star}$ & $0.560,0.856$ \\
\hline Income (FPL) & 1.016 & $0.963,1.072$ & 1.016 & $0.964,1.072$ & $1 \cdot 204^{\star \star \star}$ & $1.114,1.301$ & $1.203^{\star \star \star}$ & $1.114,1.300$ & $0.824^{\star \star \star}$ & $0.785,0.864$ & $0.823^{\star \star \star}$ & $0.785,0.864$ \\
\hline \multicolumn{13}{|l|}{ Race/ethnicity } \\
\hline White & \multicolumn{2}{|r|}{ Ref. } & \multicolumn{2}{|r|}{ Ref. } & \multicolumn{2}{|r|}{ Ref. } & & Ref. & & Ref. & & Rref. \\
\hline Black & $1.395^{\star *}$ & $1.123,1.733$ & 1.150 & $0.653,2.025$ & $0.642^{\star \star \star}$ & $0.508,0.811$ & 0.749 & $0.376,1.493$ & 1.205 & $0.978,1.483$ & $0.530^{*}$ & $0.308,0.913$ \\
\hline US Lat & 1.135 & $0.860,1.499$ & 0.882 & $0.461,1.684$ & 1.066 & $0.828,1.373$ & 1.156 & $0.615,2.173$ & $1 \cdot 141$ & $0.875,1.489$ & 0.843 & $0.452,1.571$ \\
\hline FB Lat & 0.746 & $0.553,1.007$ & $0.467^{\star \star}$ & $0.269,0.809$ & 0.983 & $0.757,1.277$ & 1.401 & $0.805,2.438$ & $1 \cdot 291^{*}$ & $1.010,1.649$ & 0.650 & $0.394,1.073$ \\
\hline Family size & $1.061^{\star}$ & $1.012,1.111$ & $1.060^{*}$ & $1.013,1.110$ & $0.901^{*}$ & $0.826,0.983$ & $0.901^{*}$ & $0.827,0.983$ & 1.038 & $0.991,1.088$ & 1.036 & $0.988,1.086$ \\
\hline Nutr. activ. index & $0.982^{*}$ & $0.968,0.997$ & $0.975^{\star}$ & $0.955,0.995$ & 0.997 & $0.981,1.013$ & 1.001 & $0.982,1.021$ & $0.928^{\star \star \star}$ & $0.911,0.946$ & $0.911^{\star \star \star}$ & $0.886,0.936$ \\
\hline Interaction terms & & & & & & & & & & & & \\
\hline Black × nutr. activ. & & & 1.015 & $0.977,1.055$ & & & 0.988 & $0.946,1.033$ & & & $1.066^{\star \star}$ & $1.024,1.109$ \\
\hline US Lat $\times$ nutr. activ. & & & 1.021 & $0.976,1.067$ & & & 0.994 & $0.956,1.032$ & & & 1.026 & $0.979,1.074$ \\
\hline FB Lat $\times$ nutr. activ. & & & 1.035 & $0.998,1.074$ & & & 0.974 & $0.939,1.011$ & & & $1.053^{\star *}$ & $1.015,1.092$ \\
\hline
\end{tabular}

Div/wid/sep, divorced/widowed/separated; HS, high school; FPL, federal poverty level; US Lat, US-born Latino; FB Lat, foreign-born Latino; nutr. activ., nutrition activation; ref., reference category.

Outcomes are for day 1 of the dietary recall. Each model further adjusts for day of the week.

${ }^{\star} P<0.05,{ }^{* \star} P<0.01,{ }^{* * *} P<0.001$. 
Table 4 Linear regression models predicting daily energy consumption, National Health and Nutrition Examination Survey 2007-2010 ( $n$ 7765)

\begin{tabular}{|c|c|c|c|c|c|c|c|c|}
\hline & \multicolumn{2}{|c|}{ (1) } & \multicolumn{2}{|c|}{$(2)$} & \multicolumn{2}{|c|}{ (3) } & \multicolumn{2}{|c|}{ (4) } \\
\hline & $b$ & $95 \% \mathrm{Cl}$ & $b$ & $95 \% \mathrm{Cl}$ & $b$ & $95 \% \mathrm{Cl}$ & $b$ & $95 \% \mathrm{Cl}$ \\
\hline Age & $-6 \cdot 820^{\star \star \star}$ & $-8 \cdot 425,-5 \cdot 214$ & $-6 \cdot 774^{\star \star \star}$ & $-8.373,-5.174$ & $-6 \cdot 830^{\star \star \star}$ & $-8.433,-5.227$ & $-6 \cdot 821^{\star \star \star}$ & $-8.435,-5.206$ \\
\hline Male gender & $596 \cdot 7^{\star \star \star}$ & $536.9,656.5$ & $598 \cdot 3^{\star \star \star}$ & $538.7,657.9$ & $597 \cdot 0^{\star \star \star}$ & $537.5,656.6$ & $597 \cdot 5^{\star \star \star}$ & $535 \cdot 8,659 \cdot 2$ \\
\hline \multicolumn{9}{|l|}{ Marital status } \\
\hline Married & \multicolumn{2}{|c|}{ Ref. } & \multicolumn{2}{|c|}{ Ref. } & \multicolumn{2}{|c|}{ Ref. } & \multicolumn{2}{|c|}{ Ref. } \\
\hline Never married & $-94 \cdot 50^{\star \star}$ & $-155.4,-33.56$ & $-95 \cdot 27^{\star \star}$ & $-156 \cdot 1,-34.43$ & $-94 \cdot 33^{\star *}$ & $-155 \cdot 3,-33.32$ & $-94 \cdot 68^{\star \star}$ & $-156 \cdot 1,-33.30$ \\
\hline Div/wid/sep & 23.93 & $-44.56,92 \cdot 42$ & $24 \cdot 34$ & $-43 \cdot 52,92 \cdot 20$ & 24.39 & $-44.11,92.88$ & 24.25 & $-44.18,92.69$ \\
\hline \multicolumn{9}{|l|}{ Educational attainment } \\
\hline$<\mathrm{HS}$ & \multicolumn{2}{|c|}{ Ref. } & \multicolumn{2}{|c|}{ Ref. } & \multicolumn{2}{|c|}{ Ref. } & \multicolumn{2}{|c|}{ Ref. } \\
\hline HS & 49.71 & $-34 \cdot 16,133 \cdot 6$ & 49.47 & $-33.94,132.9$ & 47.74 & $-36.95,132.4$ & 49.13 & $-35 \cdot 10,133.4$ \\
\hline$>\mathrm{HS}$ & $60 \cdot 76$ & $-7.446,129.0$ & 60.58 & $-7 \cdot 630,128.8$ & 58.63 & $-10 \cdot 16,127 \cdot 4$ & 60.54 & $-7 \cdot 620,128.7$ \\
\hline Income (FPL) & $24.61^{\star \star}$ & $10.39,38.83$ & $24 \cdot 21^{\star *}$ & $9.931,38.49$ & $24.89^{\star \star}$ & $10 \cdot 61,39 \cdot 16$ & $24.65^{\star \star}$ & $10.43,38.87$ \\
\hline \multicolumn{9}{|l|}{ Race/ethnicity } \\
\hline White & \multicolumn{2}{|c|}{ Ref. } & \multicolumn{2}{|c|}{ Ref. } & \multicolumn{2}{|c|}{ Ref. } & \multicolumn{2}{|c|}{ Ref. } \\
\hline Black & $-58 \cdot 12^{\star}$ & $-111.1,-5.088$ & $-134 \cdot 5^{\star \star \star}$ & $-206 \cdot 0,-62.99$ & $-62 \cdot 03^{*}$ & $-120 \cdot 6,-3.446$ & $29 \cdot 21$ & $-164 \cdot 0,222 \cdot 5$ \\
\hline US Lat & 10.92 & $-102 \cdot 3,124 \cdot 1$ & -28.94 & $-173.5,115 \cdot 7$ & -31.25 & $-151 \cdot 2,88 \cdot 74$ & $49 \cdot 24$ & $-194.0,292.5$ \\
\hline FB Lat & $-98 \cdot 27^{\star}$ & $-177 \cdot 1,-19 \cdot 41$ & $-110 \cdot 1^{\star}$ & $-198 \cdot 2,-22 \cdot 00$ & $-106 \cdot 1^{*}$ & $-191 \cdot 1,-21 \cdot 14$ & $-132 \cdot 8$ & $-351.4,85.85$ \\
\hline Family size & -10.57 & $-27.62,6.476$ & -10.06 & $-27 \cdot 25,7 \cdot 140$ & -10.43 & $-27.41,6.550$ & -10.44 & $-27.40,6.523$ \\
\hline Nutr. activ. index & $-12 \cdot 81^{\star \star \star}$ & $-17.88,-7.753$ & $-12 \cdot 68^{\star \star \star}$ & $-17.75,-7.608$ & $-12 \cdot 82^{\star \star \star}$ & $-17.90,-7.740$ & $-11.90^{\star *}$ & $-18.75,-5.038$ \\
\hline Ate fast food & $199 \cdot 7^{\star \star \star}$ & $128.4,270.9$ & $162 \cdot 0^{\star \star \star}$ & $74 \cdot 88,249 \cdot 1$ & $199 \cdot 8^{\star \star \star}$ & $128.5,271.0$ & $198 \cdot 3^{\star \star \star}$ & $127 \cdot 5,269 \cdot 1$ \\
\hline Ate restaurant food & $143 \cdot 1^{\star *}$ & $55 \cdot 75,230 \cdot 4$ & $143 \cdot 6^{\star *}$ & $57.63,229.6$ & $129 \cdot 7^{*}$ & $27 \cdot 88,231.5$ & $143 \cdot 3^{\star \star}$ & $56 \cdot 19,230 \cdot 4$ \\
\hline No. of SSB & $191 \cdot 0^{\star \star \star *}$ & $156 \cdot 6,225 \cdot 4$ & $191 \cdot 5^{\star \star \star}$ & $156 \cdot 8,226 \cdot 1$ & $191 \cdot 0^{\star \star \star}$ & $156 \cdot 4,225.5$ & $191 \cdot 6^{\star \star \star}$ & $157 \cdot 8,225 \cdot 3$ \\
\hline No. of diet beverages & -9.645 & $-48 \cdot 37,29.08$ & -8.849 & $-47 \cdot 64,29 \cdot 94$ & $-9 \cdot 176$ & $-48.04,29.69$ & -9.550 & $-48 \cdot 39,29 \cdot 29$ \\
\hline No. of alcoholic beverages & $211 \cdot 6^{\star \star \star}$ & $156 \cdot 7,266 \cdot 5$ & $211.3^{\star \star \star}$ & $156 \cdot 5,266 \cdot 2$ & $211 \cdot 8^{\star \star \star}$ & $157 \cdot 2,266 \cdot 4$ & $211 \cdot 2^{\star \star \star}$ & $155 \cdot 9,266 \cdot 4$ \\
\hline \multicolumn{9}{|l|}{ Interaction terms } \\
\hline Black × fast food & & & $216 \cdot 0^{*}$ & $44.43,387.5$ & & & & \\
\hline US Lat $\times$ fast food & & & $113 \cdot 1$ & $-166 \cdot 4,392 \cdot 6$ & & & & \\
\hline FB Lat $\times$ fast food & & & 38.95 & $-121 \cdot 1,199.0$ & & & & \\
\hline Black $\times$ restaurant food & & & & & $18 \cdot 34$ & $-188 \cdot 3,224 \cdot 9$ & & \\
\hline US Lat $\times$ restaurant food & & & & & 185.5 & $-61.60,432.6$ & & \\
\hline FB Lat $\times$ restaurant food & & & & & 39.27 & $-139 \cdot 7,218 \cdot 3$ & & \\
\hline Black $\times$ nutr. activ. & & & & & & & $-6 \cdot 538$ & $-21 \cdot 36,8 \cdot 287$ \\
\hline US Lat $\times$ nutr. activ. & & & & & & & -3.018 & $-18.53,12.50$ \\
\hline FB Lat $\times$ nutr. activ. & & & & & & & $2 \cdot 323$ & $-10 \cdot 46,15 \cdot 11$ \\
\hline
\end{tabular}

Div/wid/sep, divorced/widowed/separated; HS, high school; FPL, federal poverty level; US Lat, US-born Latino; FB Lat, foreign-born Latino; nutr. activ., nutrition activation; SSB, sugar-sweetened beverages; ref., reference category.

The outcome is mean daily energy consumption across both days of dietary recall, measured in kilocalories $(1 \mathrm{kcal}=4.184 \mathrm{~kJ})$.

${ }^{\star} P<0.05,{ }^{* \star} P<0.01,{ }^{* \star \star} P<0.001$. 
nutritional literacy regarding SSB may be lower among these groups. Strategies for decreasing SSB consumption among blacks and foreign-born Latinos should thus focus both on increasing activation and developing culturally competent, comprehensible SSB labels and healthy beverage marketing campaigns.

The present study has a number of important limitations. As with any observational study, it is impossible to establish causality between independent and dependent variables. An unknown portion of observed associations could be due to confounding (i.e. an unmeasured third variable may cause consumers to become more activated and to eat better). We attempted to minimize the likelihood of confounding via multivariable analyses controlling for income, education and other sociodemographic characteristics. It is important to highlight that we were unable to explicitly control for many psychosocial, sociocultural and food environmental factors that are likely to vary by race/ethnicity and may impact both nutrition activation and diet (e.g. food advertising is tailored and targeted differently based on race/ethnicity, is explicitly intended to impact food choice and may impact nutrition activation). These unobserved differences likely drive a portion of racial/ethnic disparities in diet and may represent an unknown bias on our observations regarding the association between nutrition activation and diet. The majority of our measures are based on participant selfreport and thus subject to recall bias, social desirability bias and other forms of measurement error. As a secondary analysis, our study was limited in its component measures of nutrition activation. Although we feel confident that NHANES measures important subdimensions of the larger nutrition activation construct, it is likely that additional sub-dimensions may not have been included. This limitation notwithstanding, we conducted a principal components factor analysis and found that our component measures of nutrition activation loaded strongly on the same factor. As a sensitivity analysis, we conducted all multivariable analyses using the additive index as well as the scale derived from the factor analysis. For all models, outcomes were qualitatively equivalent, so we chose to use the additive index for the sake of simplicity. Similarly, we conducted sensitivity analyses regarding our use of logistic regression models to examine determinants of SSB consumption. Findings between logistic and ordered logit models were extremely similar, so we chose to include logistic models because of their more approachable interpretation.

We believe the study also has notable strengths. NHANES is a rigorously conducted, nationally representative study and thus highly generalizable. Furthermore, the study includes a broad range of nutrition- and diet-related variables, which enabled us to construct a reasonable measure of nutrition activation. The present study is one of few of which we are aware to assess racial/ ethnic variation in active use of nutrition information as well as the impact of that use on food behaviours. This approach has elucidated several pathways that may contribute to important health disparities. Further research should be conducted to develop more robust, systematic and multidimensional measures of nutrition activation and confirm our findings.

\section{Conclusions}

In conclusion, nutrition activation is an important determinant of food behaviours, varies within and between racial/ethnic groups, and has significant room for improvement. Across racial/ethnic groups, improved nutrition activation is consistently associated with decreased frequency of restaurant-food consumption and lower daily energy intake. Interventions to improve nutrition activation among all populations may be a useful but understudied strategy to combat secular increases in obesity. Importantly, we found that blacks and foreignborn Latinos consumed more SSB than whites, but highly activated consumers from these groups received less of a protective effect against SSB consumption than their white counterparts. This suggests that development of culturally competent beverage labels and marketing campaigns may be a useful strategy for curbing disparately high SSB consumption among blacks and foreign-born Latinos.

\section{Acknowledgements}

Financial support: This work was supported by the Robert Wood Johnson Foundation New Connections programme (B.A.L., grant number 73267). The funder had no role in the design, analysis or writing of this article. Conflict of interest: None. Authorship: B.A.L. and P.M.M. each contributed to the conceptualization of the study, analytic plan and interpretation of results. B.A.L. conducted the analyses and drafted the manuscript. B.A.L. and P.M.M. collaborated to edit the final draft of the manuscript. Ethics of buman subject participation: The study used publicly available data that do not contain personally identifying information, thus it does not meet the definition of human subjects research and no institutional review board approval was sought.

\section{References}

1. US Department of Health and Human Services (2010) The Surgeon General's Vision for a Healthy and Fit Nation. Rockville, MD: US Department of Health and Human Services, Office of the Surgeon General.

2. Flegal K, Carroll M, Kit B et al. (2012) Prevalence of obesity and trends in the distribution of body mass index among US adults, 1999-2010. JAMA 307, 491-497.

3. Flegal KM, Carroll MD, Ogden CL et al. (2010) Prevalence and trends in obesity among US adults, 1999-2008. JAMA 303, 235-241. 
4. Narayan KMV, Boyle JP, Thompson TJ et al. (2003) Lifetime risk for diabetes mellitus in the United States. JAMA $\mathbf{2 9 0}$ 1884-1890

5. Martin LT, Ruder T, Escarce JJ et al. (2009) Developing predictive models of health literacy. J Gen Intern Med $\mathbf{2 4}$ 1211-1216.

6. Hill JO (2006) Understanding and addressing the epidemic of obesity: an energy balance perspective. Endocr Rev 27, 750-761.

7. Guthe CE \& Mead M; National Research Council Committee on Food Habits (1943) The Problem of Changing Food Habits: Report of the Committee on Food Habits, 1941-1943. Washington, DC: National Research Council, National Academy of Sciences.

8. Glanz K, Sallis JF, Saelens BE et al. (2005) Healthy nutrition environments: concepts and measures. Am J Health Promot 19, 330-333.

9. Diez-Roux AV, Nieto FJ, Caulfield L et al. (1999) Neighbourhood differences in diet: the Atherosclerosis Risk in Communities (ARIC) Study. I Epidemiol Community Health 53, 55-63.

10. Moore LV, Diez Roux AV, Nettleton JA et al. (2009) Fast-food consumption, diet quality, and neighborhood exposure to fast food: the multi-ethnic study of atherosclerosis. Am J Epidemiol 170, 29-36.

11. Langellier BA, Brookmeyer R, Wang MC et al. (2015) Language use affects food behaviours and food values among Mexican-origin adults in the USA. Public Health Nutr 18, 264-274.

12. Beech BM, Rice R, Myers L et al. (1999) Knowledge, attitudes, and practices related to fruit and vegetable consumption of high school students. I Adolesc Health 24, 244-250.

13. Drewnowski A (2009) Obesity, diets, and social inequalities. Nutr Rev 67, Suppl. 1, S36-S39.

14. Darmon N \& Drewnowski A (2008) Does social class predict diet quality? Am J Clin Nutr 87, 1107-1117.

15. Shohaimi S, Welch A, Bingham S et al. (2004) Residential area deprivation predicts fruit and vegetable consumption independently of individual educational level and occupational social class: a cross sectional population study in the Norfolk cohort of the European Prospective Investigation into Cancer (EPIC-Norfolk). J Epidemiol Community Health 58, 686-691.

16. Drewnowski A \& Specter SE (2004) Poverty and obesity: the role of energy density and energy costs. Am J Clin Nutr $\mathbf{7 9}$, 6-16.

17. Morland K, Wing S, Diez Roux A et al. (2002) Neighborhood characteristics associated with the location of food stores and food service places. Am J Prev Med 22, 23-29.

18. Galvez MP, Morland K, Raines C et al. (2008) Race and food store availability in an inner-city neighbourhood. Public Health Nutr 11, 624-631.

19. Boone-Heinonen J, Gordon-Larsen P, Kiefe CI et al. (2011) Fast food restaurants and food stores longitudinal associations with diet in young to middle-aged adults: the CARDIA study. Arch Intern Med 171, 1162-1170.

20. Bowman SA, Gortmaker SL, Ebbeling CB et al. (2004) Effects of fast-food consumption on energy intake and diet quality among children in a national household survey. Pediatrics 113, 112-118.

21. Bowman SA \& Vinyard BT (2004) Fast food consumption of US adults: impact on energy and nutrient intakes and overweight status. J Am Coll Nutr 23, 163-168.

22. Duffey KJ, Gordon-Larsen P, Jacobs DR et al. (2007) Differential associations of fast food and restaurant food consumption with 3-y change in body mass index: the Coronary Artery Risk Development in Young Adults Study. Am J Clin Nutr 85, 201-208.

23. Nocella G \& Kennedy O (2012) Food health claims - what consumers understand. Food Policy 37, 571-580.
24. Fraser B (2013) Latin American countries crack down on junk food. Lancet 382, 385-386.

25. Miller LMS \& Cassady DL (2012) Making healthy food choices using nutrition facts panels. The roles of knowledge, motivation, dietary modifications goals, and age. Appetite 59, 129-139.

26. Temple NJ \& Fraser J (2014) Food labels: a critical assessment. Nutrition 30, 257-260.

27. Rothman RL, Housam R, Weiss H et al. (2006) Patient understanding of food labels: the role of literacy and numeracy. Am J Prev Med 31, 391-398.

28. Nelson D, Graham D \& Harnack L (2014) An objective measure of nutrition facts panel usage and nutrient quality of food choice. J Nutr Educ Behav 46, 589-594.

29. Huizinga MM, Carlisle AJ, Cavanaugh KL et al. (2009) Literacy, numeracy, and portion-size estimation skills. Am J Prev Med 36, 324-328.

30. Weiss BD, Mays MZ, Martz W et al. (2005) Quick assessment of literacy in primary care: the newest vital sign. Ann Fam Med 3, 514-522.

31. Nutbeam D (2008) The evolving concept of health literacy. Soc Sci Med 67, 2072-2078.

32. Massey P, Prelip M, Calimlim B et al. (2013) Findings toward a multidimensional measure of adolescent health literacy. Am J Health Behav 37, 342-350.

33. Sharif MZ, Rizzo S, Prelip ML et al. (2014) The association between nutrition facts label utilization and comprehension among Latinos in two East Los Angeles neighborhoods. J Acad Nutr Diet 114, 1915-1922.

34. Pleasant A, McKinney J \& Rikard R (2011) Health literacy measurement: a proposed research agenda. $J$ Health Commun 16, 11-21.

35. Hibbard JH \& Greene J (2013) What the evidence shows about patient activation: better health outcomes and care experiences; fewer data on costs. Health Aff (Millwood) 32, 207-214.

36. Greene J \& Hibbard JH (2012) Why does patient activation matter? An examination of the relationships between patient activation and health-related outcomes. $J$ Gen Intern Med 27, 520-526.

37. Hibbard JH, Greene J, Becker ER et al. (2008) Racial/ethnic disparities and consumer activation in health. Health Aff (Millwood) 27, 1442-1453.

38. Hibbard JH, Greene J \& Overton V (2013) Patients with lower activation associated with higher costs; delivery systems should know their patients' 'scores'. Health Aff (Millwood) 32, 216-222.

39. Hibbard JH, Greene J \& Tusler M (2009) Improving the outcomes of disease management by tailoring care to the patient's level of activation. Am J Manag Care 15, 353-360.

40. Remmers C, Hibbard J, Mosen DM et al. (2009) Is patient activation associated with future health outcomes and healthcare utilization among patients with diabetes? I Ambul Care Manag 32, 320-327.

41. Gazmararian JA, Kripalani S, Miller MJ et al. (2006) Factors associated with medication refill adherence in cardiovascular-related diseases: a focus on health literacy. J Gen Intern Med 21, 1215-1221.

42. Hanchate AD, Ash AS, Gazmararian JA et al. (2008) The Demographic Assessment for Health Literacy (DAHL): a new tool for estimating associations between health literacy and outcomes in national surveys. J Gen Intern Med 23, 1561-1566.

43. Satia-Abouta J (2003) Dietary acculturation: definition, process, assessment, and implications. Int J Hum Ecol 4, 71-86.

44. Ayala GX, Baquero B \& Klinger S (2008) A systematic review of the relationship between acculturation and diet among latinos in the United States: implications for future research. I Am Diet Assoc 108, 1330-1344.

45. Blanck HM, Gillespie C, Kimmons JE et al. (2008) Trends in fruit and vegetable consumption among US men and women, 1994-2005. Prev Chronic Dis 5, A35. 
46. Block JP, Scribner RA \& DeSalvo KB (2004) Fast food, race/ ethnicity, and income - a geographic analysis. Am J Prev Med 27, 211-217.

47. Palloni A (2006) Reproducing inequalities: luck, wallets, and the enduring effects of childhood health. Demography $\mathbf{4 3}$, 587-615.

48. Hiza HAB, Casavale KO, Guenther PM et al. (2013) Diet quality of Americans differs by age, sex, race/ethnicity, income, and education level. J Acad Nutr Diet 113, 297-306.

49. Kling JR, Liebman JB \& Katz LF (2007) Experimental analysis of neighborhood effects. Econometrica 75, 83-119.

50. US Department of Health and Human Services, Centers for Disease Control and Prevention, National Center for Health Statistics (2007) National Health and Nutrition Examination Survey, 2007-2008: Overview. Hyattsville, MD: US Department of Health and Human Services.

51. Lara M, Gamboa C, Kahramanian MI et al. (2004) Acculturation and Latino health in the United States: a review of the literature and its sociopolitical context. Annu Rev Public Health 26, 367-397.

52. Go AS, Mozaffarian D, Roger VL et al. (2013) Heart disease and stroke statistics - 2013 update: a report from the American Heart Association. Circulation 127, e6-e245.
53. Abraído-Lanza AF, Chao MT \& Flórez KR (2005) Do healthy behaviors decline with greater acculturation? Implications for the Latino mortality paradox. Soc Sci Med 61, 1243-1255.

54. Markides KS \& Coreil J (1986) The health of Hispanics in the southwestern United States: an epidemiologic paradox. Public Health Rep 101, 253-265.

55. Palloni A \& Arias E (2004) Paradox lost: explaining the hispanic adult mortality advantage. Demography $\mathbf{4 1}$, 385-415.

56. Rooks RN, Wiltshire JC, Elder K et al. (2012) Health information seeking and use outside of the medical encounter: is it associated with race and ethnicity? Soc Sci Med $\mathbf{7 4}$, 176-184.

57. Richardson A, Allen JA, Xiao H et al. (2012) Effects of race/ ethnicity and socioeconomic status on health informationseeking, confidence, and trust. $J$ Health Care Poor Underserved 23, 1477-1493.

58. Lubetkin EI, Zabor EC, Isaac K et al. (2015) Health literacy, information seeking, and trust in information in Haitians. Am J Health Behav 39, 441-450.

59. Lin B-H, Smith TA, Lee J-Y et al. (2011) Measuring weight outcomes for obesity intervention strategies: the case of a sugar-sweetened beverage tax. Econ Hum Biol 9, 329-341. 